Community Health Care Development 


\section{Community Health Care Series}

Series Editor: Professor David Sines

Deborah Hennessy (ed.)

Community Health Care Development

Carolyn Mason (ed.)

Achieving Quality in Community Health Care

John Øvretveit, Peter Mathias and Tony Thompson (eds)

Interprofessional Working for Health and Social Care

\section{Community Health Care Series}

Series Standing Order ISBN 978-0-333-64692-2

You can receive future titles in this series as they are published by placing a standing order. Please contact your bookseller or, in the case of difficulty, write to us at the address below with your name and address, the title of the series and the ISBN quoted above.

Customer Services Department, Macmillan Distribution Ltd, Houndmills, Basingstoke, Hampshire, RG21 6XS, England 


\title{
Community Health Care Development
}

\author{
Edited by \\ DEBORAH HENNESSY
}

Foreword by Andrew Wall

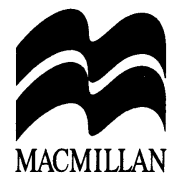


Selection, editorial matter and Introduction (C) Deborah Hennessy 1997

Preface (C) David Sines 1996, 1997

Foreword (C) Andrew Wall 1997

Individual chapters (in order) $\mathbb{C}$ Deborah Hennessy and Geraldine Swain; Lesley Armitage; Liz Haggard; Caroline Taylor and Geoff Meads; Ainna Fawcett-Henesy; Rita Bell, Kath Johnson and Heather Scott; Kieran Walshe; Neil Small, Audrey Ashworth, Douglas Coyle, Sue Hennessy, Sue Jenkins-Clarke, Nigel Rice and Sam Ahmedzai; Lucy Hadfield; Sandra Legg and Helena Ellerington; Deborah Hennessy and Geraldine Swain 1997

All rights reserved. No reproduction, copy or transmission of this publication may be made without written permission.

No paragraph of this publication may be reproduced, copied or transmitted save with written permission or in accordance with the provisions of the Copyright, Designs and Patents Act 1988, or under the terms of any licence permitting limited copying issued by the Copyright Licensing Agency, 90 Tottenham Court Road, London W1P 9HE.

Any person who does any unauthorised act in relation to this publication may be liable to criminal prosecution and civil claims for damages.

The authors have asserted their rights to be identified as the authors of this work in accordance with the Copyright, Designs and Patents Act 1988.

First published 1997 by

MACMILLAN PRESS LTD

Houndmills, Basingstoke, Hampshire RG21 6XS

and London

Companies and representatives

throughout the world

ISBN 978-0-333-64692-2

DOI 10.1007/978-1-349-13906-4

ISBN 978-1-349-13906-4 (eBook)

A catalogue record for this book is available from the British Library.

This book is printed on paper suitable for recycling and made from fully managed and sustained forest sources.

$\begin{array}{llllllllll}10 & 9 & 8 & 7 & 6 & 5 & 4 & 3 & 2 & 1\end{array}$

$\begin{array}{llllllllll}06 & 05 & 04 & 03 & 02 & 01 & 00 & 99 & 98 & 97\end{array}$

Copy-edited and typeset by Povey-Edmondson Tavistock and Rochdale, England 
Dedicated with love to the Sisters of the Community of St John the Divine, Alum Rock Road, Birmingham, who as an Anglican Religious Nursing Order have given compassionate care in the development of community health since 1848 
List of Figures

ix

List of Tables

$\mathrm{X}$

Foreword by Andrew Wall xi

Preface by Professor David Sines xiii

Acknowledgements $\quad \mathrm{xv}$

List of Contributors $\quad$ xvi

Introduction $\quad 1$

Deborah Hennessy

1. Developing community health care 3

Deborah Hennessy and Geraldine Swain

2. Identifying health needs

Lesley E. Armitage

3. Commissioning services to meet identified needs

Liz Haggard

4. The development of primary care

Caroline Taylor and Geoff Meads

5. Inner-city changes: health care services in Britain's inner cities

Ainna Fawcett-Henesy

6. Interprofessional education and curriculum development: 'A Model for the Future'

Rita Bell, Kath Johnson, Heather Scott

7. Clinical effectiveness: the challenge for community nursing

Kieran Walshe

8. Palliative care in the community

Neil Small, Audrey Ashworth, Douglas Coyle,

Sue Hennessy, Sue Jenkins-Clarke, Nigel Rice and

Sam Ahmedzai 
9. How to deliver effective community health care Lucy Hadfield

10. The effect of changes in hospital care on community health care

Sandra Legg and Helena Ellerington

11. Epilogue

Deborah Hennessy and Geraldine Swain

Index of Names

Index of Subjects 
2.1 Diagram showing the relationship between need, supply and demand

2.2 Scoring grid to assist in the determination of priorities

6.1 Taxonomy of primary health care: a framework for interprofessional education

7.1 Definition of evidence-based health care

7.2 Publications indexed on CINAHL by year of publication

9.1 NHS key stakeholders and their roles

10.1 Organisational change resulting from new technologies

10.2 The political, economic and technical trends which have influenced changes in acute care 
1.1 The development of NHS reforms 17

4.1 Primary care development (a motivational matrix) 96

6.1 National occupational standards and associated qualifications

6.2 Interprofessional initiatives by geographical distribution and combination of professions 136

7.1 Effective Health Care bulletins 170

7.2 Interventions to promote change 172

8.1 Hospice services in the UK and Republic of Ireland 180

8.2 Death rates per million population from common conditions in England

8.3 Place of death in 1991 of patients who were identified as having a terminal or palliative period in one health region

8.4 Socio-demographic characteristics of patients, recruited from the community

8.5 Medical characteristics of recruited patients, community

8.6 Profile of carers in the community

8.7 Number of patients receiving visits from GPs and nurses in the week before completion of baseline data 
Care started in the community. In the most primitive societies there were no alternatives to caring at home. But with the developing sophistication of civilisations health care went beyond the home and people other than the immediate family became involved. And with this came problems which we are now beginning to recognise and are attempting to alleviate.

As care became more institutionalised so the family became more distanced. The normal responses based on day-to-day knowledge of the sick person could no longer be relied upon and nurses and others had to learn to become proxies for the family and learn to understand their patient. In an institution this is difficult because there is no prompting from the patient's own context. We now are attempting to redress the situation both by treating the patient at home for as long as possible and when they have to be admitted encouraging the care staff to acknowledge the patient as a complete individual, not just a set of symptoms.

This regard for the wholeness of the patient is one of the differences between primary care and community care. Primary care is about the time and place of treatment but community care comprehends the person in their own setting. The simplistic divide between primary (good) and secondary (bad) therefore fails to recognise the uniqueness of each individual and how that uniqueness needs to be understood at every point along the continuum of care.

Given the intimate knowledge that all care workers need to have of those they are looking after, values and standards arising from those values need to be articulated. These values have sometimes been politically motivated: community care was thought to be a cheaper option. Or they can lead to dogmatism: community care is always best. But both these views are flawed. Community care can be very expensive - think about twenty-four-hour home care - and treating people at home is beneficial only if their full clinical needs can be met. So the values need to be centred much more on appropriateness.

Community care can create other problems. One of the reasons for preferring institutional settings for care has been to standardise practice. This has of course been the keystone of professionalism. But how can this work in the community? Will the patient be put to unnecessary risk when care workers are relatively unsupervised? 
Community care is diffuse and therefore more difficult to manage. This is a challenge to managers who, by their very nature, are concerned with control. They may react unfavourably to what they may see as a sentimental approach to patients which in fact camouflages poor practice and inefficient use of resources.

Community care is at the heart of today's health care rhetoric. What this book does so valuably is to explore the reality of community care and re-establish that, fundamentally, community care is about recognising the supremacy of the patient and the obligations health care workers have to recognise the patient's individuality in the most appropriate manner possible. It is not easy, it is not cheap, but adherence to the highest standards never is!

\author{
ANDREW WALL \\ Health Services Management Centre \\ University of Birimingham
}


Successive governments have indicated their commitment to enhancing the health of the nation and, in recent years, the focus of care delivery has shifted with escalating speed into the community. In so doing, it has become evident that community nurses and health visitors provide the focus for the promotion of health gain, and for the maintenance of positive health status for individuals, groups and local communities. Community nurses and health visitors are destined, therefore, to become leaders in the design, delivery and evaluation of effective health care interventions, informed by academic discovery, and advanced practice skills and competencies.

The changes that confront the contemporary community nursing practitioner are characterised by the diverse nature of the context within which community care is transacted, with an increasing emphasis on inter-sectoral co-operation, interprofessional collaboration, community action and development, and reduced reliance on the acute sector and residential care provision for longer-stay client groups.

The impact of change, pushed by a growing demand for flexible, high-quality services provided within local communities, will inevitably shape the NHS of the future. Resources. have already been shifted to the community (although at a pace that is all too often criticised as being grossly inadequate to meet client need). Commissioners and providers are now required to demonstrate that the care they purchase and deliver is effective and responsive to the needs of local practice populations. To complement this, community nurses will be required to ensure that their activities make a significant impact on health gain for their practice population and, as such, should become seriously involved in structuring the political agenda that ultimately governs their practice environment.

In order for the community workforce to respond to these challenges, it will be necessary to ensure that community workers are equipped with the necessary skills and knowledge-base to be able to function effectively in the 'new world of community health practice'. Nurses will be required to develop and change, drawing upon the very best of their past experience, and becoming increasingly reliant upon the production of research evidence to inform their future practice.

This series is aimed at practising community nurses and health visitors, their students, managers, professional colleagues and 
commissioners. It has been designed to provide a broad-ranging synthesis and analysis of the major areas of community activity, and to challenge models of traditional practice. The texts have been designed specifically to appeal to a range of professional and academic disciplines. Each volume will integrate contemporary research, recent literature and practice examples relating to the effective delivery of health and social care in the community. Community nurses and health visitors are encouraged towards critical exploration and, if necessary, to change their own contribution to health care delivery - at the same time as extending the scope and boundaries of their own practice.

Authors and contributors have been carefully selected. Whether they are nurses or social scientists (or both), their commitment to the further development and enrichment of health science (and nursing as an academic discipline in particular) is unquestionable. The authors all demonstrate knowledge, experience and excellence in curriculum design, and share a commitment to excellence in service delivery. The result is a distillation of a range of contemporary themes, practice examples and recommendations that aim to extend the working environment for practising community nurses and health visitors and, in so doing, improve the health status of their local consumer.

Community Health Care Development, edited by Dr Deborah Hennessy, has been written by a range of carefully chosen selected authors. Between them, they provide a breadth of creative vision informed by a range of commissioning and practice perspectives. The book challenges community practitioners to replace conventional methods of delivery with a community action/development focus. The authors provide an excellent synopsis of health-needs assessment within the context of the present-day health service and, in so doing, examine the growing importance of clinical and costeffectiveness in health care. The text is based on a vision of an integrated primary care service and is imbued with examples from clinical practice. Readers will be challenged to adopt a proactive approach to care delivery and to act as change agents in their area of specialist practice.

David Sines

University of Ulster

Belfast 
I am indebted to Lucy Hadfield, Caroline Taylor and Kayvan Zahir who, as fellow colleagues on the King's Fund Leadership 2000 programme (funded by the NHS Executive: Women's Unit), both advised on the structure of the book and contributed to the contents.

My thanks are also extended to all other contributors who managed to meet deadlines despite very busy jobs.

Finally, both Kathryn Conchie and Joy Rule provided considerable administrative support in a charming and efficient manner.

Deborah Hennessy 
Sam Ahmedzai BSc, MBChB, FRCP is Director of Trent Palliative Care Centre and Professor at the University of Sheffield. He was Medical Director of the Leicestershire Hospice from 1985-94.

Lesley E Armitage MB CH is Honorary Research Fellow in Public Health at the Health Services Management Centre, University of Birmingham.

Audrey Ashworth BA was a Research Fellow at the Centre for Health Care Economics, University of York. Her research interests include health psychology and palliative care.

Rita Bell RGN, DN, RNT, DNT, Cert Ed is Principal Lecturer in Primary Care at the Faculty of Health, Social Work and Education, University of Northumbria.

Douglas Coyle MSc is Associate Investigator in the Clinical Epidemiology Unit at the Ottawa Civic Hospital, and Lecturer in the Department of Medicine of the University of Ottawa, Canada. His has a particular interest in the cost-effectiveness of health care provision.

Helena Ellerington RN, RM, Dip Management Studies is Professional Advisor at The United Kingdom Central Council for Nursing, Midwifery and Health Visiting. As Hospital Manager/Senior Nurse of Newbury District Hospital she led a team of multidisciplinary staff through the health reforms of the early 1990s, managing the business agenda and the contractual process.

Ainna Fawcett-Henesy RGN, RHV is Acting Regional Adviser: Nursing and Midwifery at the World Health Organisation in Copenhagen. At the time of writing this chapter she was a member of the London Implementation Group.

Lucy Hadfield BA is Chief Executive of Wandsworth Community Health Trust and has been since its inception in 1994. She has worked in a wide variety of management posts in the NHS and has 
also had experience as a Management Consultant. Lucy is a member of the Institute of Health Services Management.

Liz Haggard MA is a Fellow at the Office for Public Management, London. She has worked in the NHS for 14 years, most recently as Chief Executive of Southern Derbyshire Community Trust.

\section{Deborah Hennessy BA PhD RN RM RHV Dip Public Health Nursing is Senior Lecturer at the Health Services Management Centre, University of Birmingham. Her previous post was that of Chief Nurse, South West Thames RHA.}

Sue Hennessy BA, MA is Research Fellow at the Centre for Health Economics at the University of York. Her current research interests are palliative care, health education and addiction.

Sue Jenkins-Clarke BSc, RGN, RHV is Research Fellow at the Centre for Health Economics at the University of York. She has worked in health services research for about 16 years.

Kath Johnson, MA, BSc, RN, DN, RHV, CPT, RNT, HVT, Cert Ed, Cert IT is Senior Lecturer Primary Health Care at the Faculty of Health, Social Work and Education, University of Northumbria.

Sandra Legg RN, RM, BA, BSc, ThL, Dip Clin Counselling, FRCNNSW was appointed Director of Nursing at Cabrini Hospital. Melbourne, Australia in 1996. Prior to this, she was Chief Nurse of St George's Healthcare NHS Trust where she led nursing through the London Acute Services reforms.

Geoff Meads MA, MSc and MHSM is Professor of Health Services Development at the City University. He was a regional director of the NHSE: South and West Office from 1992-6, having been previously a FHSA Chief Executive. A Probation Officer by training, he has extensive experience in both Health and Social Services.

Nigel Rice BSc, PhD is Research Fellow at the Centre for Health Economics at the University of York. His main interest is in qualitative methods applied to health data and to quality of life measurement. 
Heather Scott BA, Dip Applied Social Studies, Dip MHSW, MBA DPhil is Principal Lecturer and Head of the Division of Primary Health Care, Faculty of Health, Social Work and Education, University of Northumbria.

Neil Small BSc (Econ), MSW, PhD is Senior Research Fellow at the Trent Palliative Care Centre and the University of Sheffield. Until September 1995 he was Principal Investigator (Palliative Care) in the Centre for Health Care Economics, University of York.

Geraldine Swain BD, RN, RHV, RNT, Dip Health Services Management, Dip Advanced Psychodynamic Counselling is in clinical practice as a psychodynamic counsellor and a freelance facilitator in NHS staff development.

Caroline Taylor BA (Hons) is deputy Chief Executive of Camden and Islington Health Authority. She has worked in Camden and Islington since 1992 when she was appointed as FHSA General Manager. She has recently led a national project on the development needs of primary care in the context of the primary care-led NHS.

Kieran Walshe, BSc, Dip HSM, MHSM is Senior Research Fellow at the Health Services Management Centre, University of Birmingham. He has been both an NHS manager and a researcher, and his research, consultancy and education activities at HSMC reflect a continuing interest in both arenas. 